\title{
Is a "Silent Revolution" in the Making in China? \\ Postmaterialist Values, and Political Attitudes and Behavior
}

\author{
Jie Chen* $\quad$ Narisong Huhe ${ }^{\dagger} \quad$ Ting Yan
}

* Southern University of Science and Technology, James Madison University, and George Washington University. Email: chen9jx@jmu.edu.

$\dagger$ The University of Strathclyde. Email: narisong.huhe@strath.ac.uk.

$\$$ Corresponding author, Chinese University of Political Science and Law. Email: yanting@cupl.edu.cn.

All authors contributed equally to the research. We thank Professor Uk Heo and three anonymous reviewers for their invaluable comments and suggestions on the earlier versions of this article. 


\section{Abstract}

Five decades ago, Inglehart for the first time described and explained an unprecedented transformation, which he called "the silent revolution," of political cultures in advanced industrial societies. Such a phenomenon was characterized with the emergence of postmaterialist values as the result of a sustained period of economic growth in those countries, and the profound impact of those values on people's political attitudes and behavior. As China has experienced extraordinary economic growth in the past several decades, has such a "silent revolution" happened in that country? The answers to this question have been far from complete or clear. Using three longitudinal, cross-sectional national surveys, we find that while the current level of postmaterialist values in China remains relatively low, such values have flourished in younger generations, and that those values do play an important role in shaping individuals' political attitudes and behavior.

Keywords: China, Postmaterialist Values, Political Support, Political Participation, and Modernization. 


\section{Is a "Silent Revolution" in the Making in China? Postmaterialist Values, and Political Attitudes and Behavior}

There seems an agreement among many social scientists in general and political scientists in particular that one of the most provocative and influential theories of social, cultural and political change is Inglehart's theory on the relationships among economic development, cultural shift, and political change. Almost five decades ago, Inglehart (1971 and 1977) for the first time cogently described and explained an unprecedented transformation, which he referred to as "the silent revolution," of political cultures in advanced industrial societies. "[T] his transformation seems to be altering the basic value priorities of given generations, as a result of changing conditions influencing their basic socialization. The changes seem to affect the stand one takes on current political issues" (Inglehart 1971, 991). Over these past decades, Inglehart and other scholars have tried to generalize his findings about the silent revolution from the then advanced industrial societies to many other societies based on data collected from a series of the World Value Surveys and other regional and national surveys.

The fundamental tenet of Inglehart's theory on the cultural transformation and its political impact, as he recently referred to as "Evolutionary Modernization" theory, is that "changing levels of economic and physical security have been reshaping human values and motivations, and thereby transforming societies" (Inglehart 2018, 8). Specifically, at the individual level, based loosely on Maslow's (1954) theory of a hierarchy of needs, Inglehart contends that as a society becomes increasingly modernized with respect to economic and physical conditions, the material needs of a population in the society are by and large fulfilled; in turn, such a population will take physical survival for granted, and shift its focus onto a higher 
level of needs or non-material needs such as self-actualization, autonomy, and self-expression. This new set of needs, known as "postmaterialist values," will lead to a new set of views about political issues, such as trust in government and individuals' role in political decision making, among others. More importantly, Inglehart argues that this transformation process driven by postmaterialist values is "not a uniquely Western phenomenon." Based on his empirical findings over several decades, Inglehart claims that this phenomenon has been found "in societies with widely different institutions and cultural traditions..... The rise of Postmaterialist values is closely linked with prosperity and seems to occur wherever a society has experienced enough economic growth in recent decades" (Inglehart 1997, 158).

Since the outset of post-Mao reforms in the late 1970s, China has become increasingly modernized in terms of its overall national economic capacity and its population's living conditions. Particularly, in the past four decades, the country's income per capita had grown fifty times, from about $\$ 200$ in 1980 to about $\$ 10,000$ in 2018 (see Figure 1). As China has experienced such an extraordinary economic growth, has a transforming phenomenon known as the "silent revolution,"-characterized with the emergence of postmaterialist values, and the profound impact of those values on individuals' political attitudes and behavior-happened in that country? While this question has a lot to do with explaining and predicting trends of sociopolitical development in China, the most populous and arguably most dynamic country in the world, there seems no consensus in the extant literature in answering the question. On the one hand, some China analysts seem to suggest that such a transformation in people's attitudes has already taken off, finding that a higher level of economic development leads to pursuit of autonomy and self-expression and critical opinions about authoritarianism and support for democracy (e.g., Wang 2005; Wang and You 2016; Zhou 2020). On the other hand, some other 
analysts contend that China serves as a "deviant case" to modernization theory because economic development seems to help engender popular support for the authoritarian regime rather than postmaterialist values and interest in democracy and democratization, particularly among the middle class (e.g., Chen 2014; Nathan 2015; Tang 2016; Wang, Wan and Hsiao 2011; Zhang, Brym and Anderson 2017).

\section{Figure 1}

\section{Growth of Income Per Capita in China: 1960-2018}

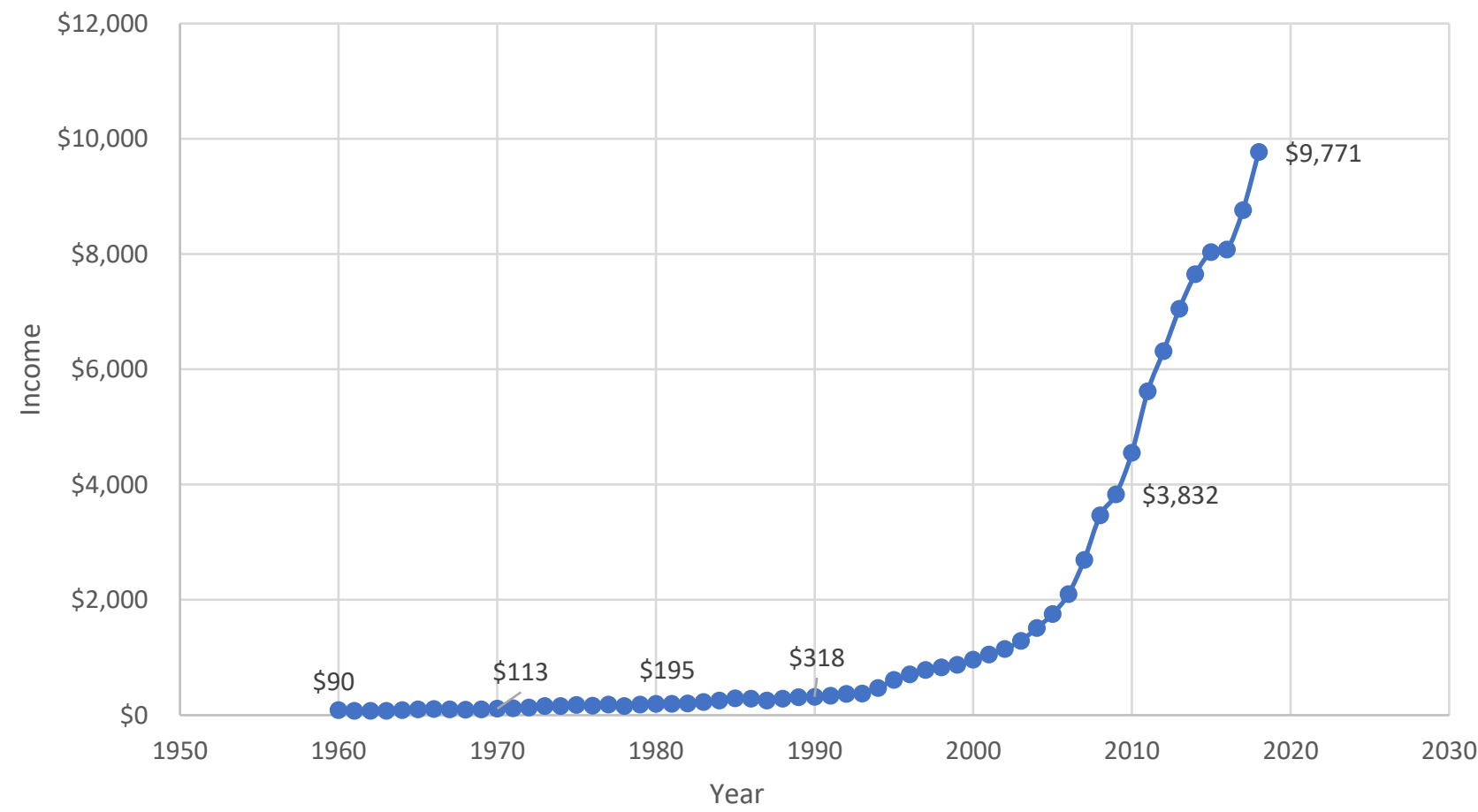

Data Source: World Bank (https://www.macrotrends.net/countries/CHN/china/gdp-percapita'>China GDP Per Capita 1960-2020. www.macrotrends.net. Retrieved 2020-07-11.) 
In addition to the absence of substantive consensus, there are some palpable methodological gaps in the literature. First, almost all exiting studies rely on one-time, snap-shot survey data, which make it difficult, if not impossible, to detect trends of postmaterialist values over time, regardless of the stability or lack thereof in the actual trends. Second, there seems some degree of inconsistency in survey instruments to detect postmaterialist values among these studies, ${ }^{4}$ which can cause some problems with the validity of measurement for those values and hence difficulties evaluating applications of Inglehart's original argument on postmaterialist values to China. And finally, there seems no clear consensus on the impact of postmaterialist values on political attitudes and behavior in China in the literature, due in a large part to the gaps mentioned above.

To help fill those gaps, this study is to examine the level and origins of postmaterialist values and the impact of those values on people's political attitudes and behavior in China. Different from most of earlier studies, our study has at least two important features concerning survey instruments and samples. Specifically, this study (1) utilizes Inglehart's original questionnaire instruments to measure postmaterialist values and other key variables, such as trust in government and unconventional political participation, and (2) relies on data collected from three longitudinal, cross-sectional national surveys conducted in China over a period of 10 years:

\footnotetext{
${ }^{4}$ While some studies use Inglehart's original questionnaire instruments derived directly from the World Value Surveys, others employ instruments that seem quite different from Inglehart's (see, e.g., Brym 2016; Zhang, Brym and Anderson 2017; Wang and You 2016; Lu, Qi, and Yu 2019; Chen and Sun 2019).
} 
three waves of the World Values Survey (WVS) ${ }^{5}$ conducted in 2007, 2013 and 2018. These two characteristics can help us close the gaps in the extant literature, as mentioned above.

In addition, we examine the impact of postmaterialist values on such political attitudes as trust in government (or political trust) and such political behavior as unconventional participation. While political trust and unconventional participation cannot exhaust all kinds of political attitudes and behaviors in China, they provide a good test of the propositions about the impact of postmaterialist values. Both political trust and unconventional participation have been regarded critical factors that have influenced and will continue to influence the trajectory of political development in China (see, e.g., O’Brien and Li 1995, 2006; O’Brien 1996; Shi 1997; Jennings 1997; Chen 2004; Li 2008; Lu and Bruce 2020). It is hoped that this study will not only help to illuminate the level and origins of postmaterialist values and its impact on political attitudes and behaviors in China, but also test some Inglehart's key propositions about postmaterialist values.

I. Inglehart's Theory and Our Expectations

In this study, we will first delineate Inglehart's theoretical arguments and empirical evidence, which relate to the level and origins of postmaterialist values and the impact of those

\footnotetext{
${ }^{5}$ For details of these surveys, see Inglehart, R., C. Haerpfer, A. Moreno, C. Welzel, K. Kizilova, J. Diez-Medrano, M. Lagos, P. Norris, E. Ponarin \& B. Puranen et al., eds. 2014. World Values Survey: All Rounds - Country-Pooled Datafile Version:

http://www.worldvaluessurvey.org/WVSDocumentationWVL.jsp. Madrid: JD Systems Institute.
} 
values on people's political attitudes and behavior in China. It should be noted parenthetically that Inglehart himself and some other scholars have tried to apply the theory of postmaterialist values to China over the past several decades.

\section{A. The Emergence and Origins of Postmaterialist Values}

Inglehart has developed a consistent view about the emergence of postmaterialist values in China that as the country's economy continues to grow, postmaterialist values will become more prevalent. For example, in 1997 he contended that "although its absolute level of Postmaterialism remains far below that of most Western countries, China seems to be on a similar trajectory" (Inglehart 1997, 147). Even most recently, Inglehart continued to claim that "for now, Postmaterialists constitute tiny minorities in ... China; but our theory predicts that if [China] continue[s] on [its] present trajector[y], a shift toward Postmaterialist values will take place when a younger generation emerges that has grown up taking survival for granted" (Inglehart 2018, 30). In sum, Inglehart suggests that China will follow or is following the trajectory of advanced industrial countries whereas postmaterialist values have become prevalent as their economies have expanded. Following this theory, the extent of postmaterialist values in China will eventually reach a level comparable to that in advanced industrial countries.

Yet, how prevalent are those values in China now? To answer this question, we will shed some light on the level of postmaterialist values in China based on the three nation-wide surveys mentioned earlier. Furthermore, to help us better assess the current state of postmaterialist values in China from a comparative perspective, we will compare the level in China with the levels in some industrialized societies in East Asia. 
In terms of the origins of postmaterialist values, Inglehart has identified at the individual level a critical sociocognitive mechanism through which a sustained period of economic growth brings about those values in almost all his studies of this subject (e.g., Inglehart 1971, 1977, 1990, 1997, 2018; Inglehart and Welzel 2005). Specifically, he argues that "we should find a higher proportion of Postmaterialists among the younger cohorts than among the old, in any society that has had sufficient economic growth during the past four or five decades so that the younger cohorts experienced substantially greater economic security during their preadult years" than the older cohorts who did not experience such security in their preadult years (italics original, Inglehart 1997, 143). In other words, economic growth causes the emergence and expansion of postmaterialist values in a country through the mechanism of sociocognitive shift among generations. In this process of sociocognitive shift, younger generations who have experienced material security in their preadult years take physical survival for granted and subsequently focus on non-material needs, such as autonomy and self-expression; these younger generations will eventually replace the older generations and hence increase the portion of postmaterialists in the country's population. As this intergenerational sociocognitive mechanism suggests, the younger generations who have experienced economic security—along with other possible factors such as education and income-are the main source of postmaterialist values.

In general, Inglehart and his associates have so far supported the intergenerational sociocognitive mechanism with empirical data collected from regional and global surveys, though with some exceptions (e.g., Inglehart 1971, 1977, 1990, 1997, 2018; Inglehart and Siemienska 1988; Inglehart and Welzel 2005). Specifically, Inglehart has found that this mechanism is applicable to almost all kinds of societies, developed/developing and democratic/non-democratic alike. His findings have also been replicated and validated by other 
survey-based studies. For example, based on nation-wide and regional surveys carried out in 1990, Gibson and his associates find that even in such a communist society as the Soviet Union, "younger Soviet generations are the most likely to hold postmaterialist values," because "they apparently experienced a sufficient amount of economic security for postmaterialist values to have developed" in their formative years (Gibson et al 1994, 22). More interestingly, later, based on data from the 1990-93 World Values Survey, Inglehart finds that another communist country, "China starts out with an extremely low proportion of Postmaterialists among its oldest cohorts, but then shows a steep upward slope... as we move to its younger cohorts" (Inglehart 1997, 147).

Based on Inglehart's theory and the earlier empirical evidence that supports the theory, we in this study expect to find that the younger generations in contemporary Chinese society, especially those who had enjoyed economic security in their preadult years, are more likely to have postmaterialist values than the older generations who had not experienced such security in their preadult years. It is hoped that our findings, based on fresh data from the most recent national surveys conducted in China, will help us better understand the role of intergenerational sociocognitive change in shaping the emergence and expansion of postmaterialist values in that country.

\section{B. The Attitudinal and Behavioral Impact of Postmaterialist Values}

As for the impact of postmaterialist values on people's political attitudes and behavior, Inglehart has unequivocally argued that the sociocognitive shift toward postmaterialist values will cause a significant change in individuals' views about politics and government, and in their political participation. As mentioned at the outset of this study, we focus on the impact of 
postmaterialist values on political trust (political attitudes) and unconventional participation (political behavior). While there have been many studies on both political trust and unconventional participation in that country (see, e.g., O'Brien and Li 1995, 2006; O'Brien 1996; Shi 1997; Jennings 1997; Chen 2004; Li 2008; Lu and Bruce 2020), very few studies have systematically examined the impact of postmaterialist values on both. ${ }^{6}$

The Attitudinal Impact. In terms of the impact of postmaterialist values on political trust, Inglehart contends that postmaterialist values that result from economic security have a strong emphasis on "individual autonomy and diminishing deference to authority" (Inglehart 1997, 296); such a sociocognitive emphasis is very likely to lead to critical views of all kinds of authorities, simply because any authorities, particularly hierarchically ordered authorities, such as the army, police and church, and government as a whole, tend to constrain individual autonomy and self-expression. Thus, postmaterialists are likely to register a lower level of trust in governmental authorities than do materialists. It is worth noting that the notion of postmaterialists developed by Inglehart is consistent with that of "critical citizens" established by Pippa Norris and her associates (e.g., Norris 1999, and 2011), which has been utilized to study trust in government world-wide. The latter suggests that "value change [toward the postmaterialist orientation] in post-industrial societies has encouraged the development of more critical citizens who question traditional sources of authority, including government" (Norris 1999, 24).

\footnotetext{
${ }^{6}$ Some exceptions are the works by Wang (2005), Wang and You (2016), and Zhou (2020).
} 
These theoretical arguments on postmaterialists' or critical citizens' attitudes toward government have been supported by empirical evidence from studies of many democratic societies (see, e.g., Inglehart 1977, 1990, 1997; Norris 1999 and 2011). But findings from some recent empirical studies of China, though very limited in quantity, seem to yield no clear consensus on the impact of postmaterialist values on trust in government and its institutions. For example, based on data from one of the WVS waves, Wang (2005) finds that self-expression values, which are said to be closely associated with postmaterialist values, do not have a significant impact on trust in China's party-state government while controlling for other factors, such as individuals' evaluation of incumbent government performance. Similarly, relying on data from two waves of the AsiaBarometer Survey, Wong et al. (2011) find that postmaterialist values, which are measured by the 4-item (rather than 12-item) questionnaire battery originally developed by Inglehart, exert no meaningful effect on trust in government or "political trust," which is measured differently than it is in Inglehart's studies, in China.

Although the findings from those earlier studies of China are somewhat different than those from many studies of democratic societies, we are still inclined to expect that those who have a strong propensity toward postmaterialist values tend be more critical of the government than those who have no or a weak tendency toward those values. This is because we strongly suspect that the characteristics of the survey samples and instruments used in this study as mentioned earlier (e.g., three nation-wide samples covering a 10-year period, and survey instruments identical to Inglehart's original survey questions) will help us confirm our expectation, which is directly based on Inglehart's theory of postmaterialist values. 
The Behavioral Impact. As far as the impact of postmaterialist values on such a political behavior as unconventional political participation is concerned, Inglehart and his associates have argued that postmaterialist values serve as a strong motivation to participate in unconventional, “elite-challenging" political behavior (e.g., Inglehart 1990 and 1997; Inglehart and Welzel 2005). Before explaining reasons that they argue for the positive impact of postmaterialist values on unconventional political behavior, we will shed some light on the nature and some key characteristics of such a behavior in comparison to conventional political behavior.

In their important study of political participation in seven countries across all continents, Sidney Verba and his associates define conventional or traditional forms of political participation as "legal acts by private citizens that are more or less directly aimed at influencing the selection of governmental personnel and the actions that they take" (Verba,, Nie, and Kim 1978, 1). By this definition, they emphasize that conventional forms of political participation is usually "regular legal political channels" (Verba,, Nie, and Kim 1978, 1). Moreover, they identify four specific forms of conventional political participation: voting, campaign activity, communal activity, and particularized contact. According to Inglehart (Inglehart 1990), these conventional participatory forms historically resulted from mass mobilization political institutions that were established during the early stages of industrialization and democratization in Western countries. These institutions, including political parties, religious organizations and labor unions, were typically hierarchically structured; naturally, those conventional forms of political participation were mobilized and directed by political elites in the hierarchically institutions. Thus, such forms of political participation can also be considered "elite-directed" participatory activities (Gibson et al. 1994, 25). 
Unlike conventional participatory forms that are usually legal, hierarchically organized, and elite-directed, however, unconventional participatory forms refer to "elite-challenging action such as boycotts, unofficial strikes, and occupying buildings in order to press political demands" (Inglehart 1997, 307). According to Inglehart $(1997,312)$, these unconventional forms of political participation are designed to "intervene directly in political decision making, rather than limiting [participants themselves] to participation by voting, in which the public gives a blank check to a given set of elites, authorizing them to make all important political decisions for the next several years..... Unconventional participation is relatively disruptive and is designed to influence specific decisions." All in all, in contrast to conventional political participation, unconventional political participation can be characterized by a certain set of political activities that are elite-challenging, disruptive (at least sometimes), and not necessarily or completely "legal" by incumbent government's standards.

Given the differences between the two kinds of political participation (i.e., conventional and unconventional) described above, Inglehart has argued and tried to prove that those who have a strong sociocognitive propensity toward postmaterialist values are more likely to participate in unconventional political activities than those who lack such a propensity. From Inglehart's works (Inglehart 1990, 1997 and 2018; Inglehart and Welzel 2005), one can extrapolate at least two important reasons for this argument. First, people with a strong preference for postmaterialist values take physical survival for granted and hence tend to "devote more time and energy to relatively remote and abstract activities such as politics" (Inglehart 1997, 312). Moreover, postmaterialists are likely to be interested in a broader range of political issues and activities than are materialists who usually focus on a limited list of issues that are related only to their immediate material needs. Second, since postmaterialists have less 
deference to authorities and stronger motivation to pursuit autonomy and self-expression than materialists, they are more likely or "readier" (Inglehart 1997, 312) to participate in unconventional activities that are elite- or authority-challenging and even disruptive.

The empirical evidence collected by Inglehart has, by and large, supported his hypothesized positive relationship between postmaterialist values and unconventional political participation, particularly in democratic societies, at the national level. For example, based on his study of 20 democratic countries, he claims that the overall success rate for confirming such a relationship is over $80 \%$ (Inglehart 1997, 315). In addition, some empirical studies conducted by other scholars apparently support this relationship. Relevant to our study, for instance, a group of scholars find empirical evidence in a former communist society, the Soviet Union, that "postmaterialism does have an independent [and positive] impact on unconventional political behavior" (Gibson et al. 1994, 27) at the individual level. Based on these earlier studies, therefore, we expect that in our three national surveys, those who have a strong preference for postmaterialist values are more likely to participate in unconventional political activities.

\section{Data and Samples}

In this study, we systematically test Inglehart's propositions about postmaterialist values based on the most recent three waves of the WVS conducted in mainland China from 2007 to 2018. The WVS by far is one of the most authoritative and most widely used datasets in 
comparative studies of public opinion. ${ }^{7}$ Since 1990 there have been six waves of the WVS conducted in mainland China (excluding Hong Kong, Macao and Taiwan). In this study, however, we focus on Waves 5, 6 and 7 of the WVS conducted in mainland China in 2007, 2013, and 2018, respectively, simply because the earlier waves of the WVS conducted in that country did not include some of main variables in which we are interested (e.g., political trust, and unconventional political participation). We believe that a systematic analysis of data from these three waves, which span over 10 years, helps us to better understand the patterns and trends of postmaterialist values as well as their origin and impact in China.

All these three waves of WVS conducted in China employed the stratified, multi-stage probability proportional to size (PPS) sampling. Wave 5 of the WVS in China was completed from March 25 to May 10, 2007, covering the adult population between the ages of 18 and 75, who lived in 23 provinces in mainland China. The sample size of that survey was 1,991 with a response rate of 78.6\%. Wave 6 of the WVS in China was conducted from November 7, 2012 to March 16, 2013. The population of the survey consisted of adults between the ages of 18 and 75 , who resided in 31 provinces of mainland China. The overall sample size of that survey was 2300 with the response rate of $65.8 \%$. Finally, Wave 7 of the WVS in China was carried out from July 7 to October12, 2018. Consistent with the earlier waves, Wave 7 covered the adult population between the ages of 18 and 75, living in the sampled districts and counties in 31 provinces of mainland China. The sample size of Wave 7 was 3036 with the response rate of $61.7 \%$. All major variables used in this study and derived from these surveys are described in Appendix A.

\footnotetext{
${ }^{7}$ For more detailed information about the WVS in general, please see https://www.worldvaluessurvey.org/wvs.jsp.
} 
It should be noted that all the waves of the WVS conducted in China adopted a crosssectional design (vs. a panel design), which does not allow us to carry out time-series or panel analyses. Based on the cross-sectional design, however, we can explore the longitudinal changes in postmaterialist values in mainland China through an age-period-cohort (APC) analysis. Specifically, with pooled data from the three waves of the WVS conducted in China, the APC analysis allows us to disentangle the impacts of three kinds of time-related effects, that is, age effect, period effect, and cohort effect. Since one of our main purposes is to explore the cohort effect — in distinction to age effect and period effect — on post-materialist values, therefore, the APC analysis is particularly relevant to our study. It should be noted that there is a collinearity relationship among the three variables, such as "Period $=$ Age + Cohort," as commonly pointed out by scholars employing APC analysis (e.g., Neundorf and Niemi 2014). In our following analysis, we focus primarily on the cohort effect (that results from the unique experiences of a cohort group of respondents) and try to distinguish the cohort effect from age effect (that results from social and biological processes of aging). In the following sections, we employ the APC analysis, as one of statistic strategies, to examine how postmaterialist values evolved and affected political attitudes and behavior in China.

\section{The Level of Postmaterialist Values}

To measure postmaterialist values, Inglehart originally developed and employed four value-sensitive questionnaire items in the early 1970s (see, e.g., Inglehart 1971). To improve the validity and reliability of the original four-item measure, Inglehart and his associates later added eight more items to form a 12-item index to gauge those values (see, e.g., Inglehart 1997 and 
2018; Inglehart and Welzel 2005). As Inglehart and his associate (Abramson and Inglehart 1995) argue, "the reason the twelve-item index is more powerful than the original (four-item index) is that together ... [twelve] goals tap an underlying dimension and increase measurement validity." However, of the limited number of survey-based studies of postmaterialist values in China, very few (if any) studies used Inglehart's original measure of postmaterialist values. Among the few studies that used Inglehart's original measure, almost none used the 12-item measure, with very few exceptions. ${ }^{8}$

To test Inglehart's theoretical propositions and assessing his and others' empirical findings, we adopted his 12-item measure to assess the level of postmaterialist values in China based on the three national surveys (see Inglehart 1997). Our respondents in each of the surveys are asked to prioritize the 12 value-laden choices. Among these choices originally designed by Inglehart and his associates, six are considered postmaterialism-oriented values, including "more say on job," "more say in government," "freedom of speech," "less impersonal society," "ideas count more than money," and "more beautiful cities;" the rest of the six are deemed materialismoriented values, including "maintain order," "maintain stable economy," "economic growth," "fight rising prices," "fight against crimes," and "strong defense forces" (see, Inglehart 1997, 126). Behind these items, Inglehart's original rationale is that the more postmaterialism-oriented items a respondent chooses, the more postmaterialistic she or he is. We thus form an index of postmaterialist values based on respondents' responses to the 12 items, ranging from 0 (indicating choosing none of the six postmaterialist values) to 6 (indicating choosing all the six postmaterialist values). This index is used in the bivariate and multivariate analyses that follow.

\footnotetext{
${ }^{8}$ Few exceptions include a study conducted by Chang and Chen (2013).
} 
The results from the 12-item index, presented in Table 1, reveal at least three important findings. First, overall, around $11 \%$ of the respondents did not choose anyone of the six postmaterialist items and earned a score of 0 ("None") in each of the three surveys. In other words, only a small portion (about 11\%) of the population was not in favor of any postmaterialist values measured in the surveys in China during the survey time. Second, an overwhelming majority (about 90\%) of the respondents chose at least one of the six postmaterialist items in each of the three surveys: a little over $60 \%, 25-26 \%$, and $1-2 \%$ of them picked one to two, three to four, and five to six postmaterialist items, respectively. These findings seem to indicate that although a clear majority of the population had somewhat positive feelings about at least one of the postmaterialist values, a relatively small portion (less than $30 \%$ ) of them could be considered solid (with a score of "medium") or pure (with a score of "high") postmaterialists in the past decade. Finally, one can easily discern the stability of the respondents' moods about postmaterialist values over the time period of the three surveys. As the results presented in Table 1 indicated, the similar portions of the respondents could be found at each of the levels of the postmaterialist index in all three surveys. 
Table 1:

The Levels of Postmaterialist Values in China: 2007, 2013 and 2018

\begin{tabular}{|l|c|c|c|}
\hline \multirow{2}{*}{ Postmaterialist Index } & \multicolumn{3}{|c|}{ Survey Year } \\
\cline { 2 - 4 } & 2007 & 2013 & 2018 \\
\hline None (0) & $10.9 \%$ & $11.5 \%$ & $11.6 \%$ \\
\hline Low (1-2) & $62.3 \%$ & $62.0 \%$ & $61.1 \%$ \\
\hline Medium (3-4) & $24.9 \%$ & $25.3 \%$ & $26.2 \%$ \\
\hline High (5-6) & $2.0 \%$ & $1.2 \%$ & $1.1 \%$ \\
\hline
\end{tabular}

Source: Data for 2007, 2013 and 2018 come from Waves 5, 6 and 7 of the World Values

Survey.

How does the level of postmaterialist values in China compare with the levels of those values in some other East Asian societies that share the similar traditional cultures rooted in Confucianism but have economic and political systems different from China's? Given the availability of survey data comparable to those used in this study, we compare our results with those from the same three waves of the WVS (i.e., Waves 5, 6 and 7) conducted in Taiwan, South Korea, and Japan. The results from the surveys conducted in these East Asian societies, along with those from the surveys conducted in mainland China, are reported in Table 2. First, one can find that in Wave 5 of the WVS, the levels of postmaterialist values in mainland China were very comparable to those in Taiwan: only $27 \%$ of the respondents in each of these societies registered a "medium/high" level of postmaterialist values. In the same wave of the WVS, however, the respondents in Japan and South Korea enjoyed substantially higher levels of postmaterialist values than did both mainland China and Taiwan, with Japan and South Korea 
having about $50 \%$ and $40 \%$ of the respondents, respectively, in the "medium/higher" category of postmaterialism. Second, as the results in Table 2 indicate, within seven years between 2006 and 2012, Taiwan seemed to be joining Japan and South Korea on a trajectory towards an increasingly postmaterialist society. For instance, in 2012, the portion of the respondents who scored "medium/high" on the postmaterialist value index in Taiwan increased from 27\% in 2006 to about 40\% in 2012 and remained at almost the same level (39\%) in 2019 (during the Wave 7 of WVS). Finally, one can find that in all the waves of the WVS (i.e., Waves 5, 6 and 7), the level of postmaterialist values remained almost unchanged in mainland China, trailing far behind the levels of those values in Japan and South Korea since 2007 and all the other three East Asian societies since 2013 (see Tables 1 and 2). 
Table 2

Comparison of Postmaterialist Values between mainland China and Other Three East Asian Societies: Waves 5 , 6 and 7 of the WVS

\begin{tabular}{|c|c|c|c|c|c|c|c|c|c|}
\hline & \multicolumn{3}{|c|}{ Wave 5 (2005-2009) } & \multicolumn{3}{|c|}{ Wave $6(2010-2014)$} & \multicolumn{3}{|c|}{ Wave 7 (2017-2020) } \\
\hline & \multicolumn{3}{|c|}{ Postmaterialist Index } & \multicolumn{3}{|c|}{ Postmaterialist Index } & \multicolumn{3}{|c|}{ Postmaterialist Index } \\
\hline Society & $\begin{array}{l}\text { None } \\
\text { (0) }\end{array}$ & $\begin{array}{l}\text { Low } \\
(1-2)\end{array}$ & $\begin{array}{l}\text { Medium/High } \\
(3-6)\end{array}$ & $\begin{array}{l}\text { None } \\
\text { (0) }\end{array}$ & $\begin{array}{l}\text { Low } \\
(1-2)\end{array}$ & $\begin{array}{l}\text { Medium/High } \\
\text { (3-6) }\end{array}$ & $\begin{array}{l}\text { None } \\
\text { (0) }\end{array}$ & $\begin{array}{l}\text { Low } \\
(1-2)\end{array}$ & $\begin{array}{l}\text { Medium/High } \\
\text { (3-6) }\end{array}$ \\
\hline $\begin{array}{l}\text { Mainland China } \\
\text { (Wave } 5 \text { in } 2007 \text {; } \\
\text { Wave } 6 \text { in } 2013 \text {; } \\
\text { Wave } 7 \text { in } 2018 . \text { ) }\end{array}$ & $10.9 \%$ & $62.3 \%$ & $26.9 \%$ & $11.5 \%$ & $62.0 \%$ & $26.5 \%$ & $11.6 \%$ & $61.1 \%$ & $27.3 \%$ \\
\hline $\begin{array}{l}\text { Taiwan (Wave } 5 \text { in } \\
\text { 2006; Wave } 6 \text { in } \\
\text { 2012; Wave } 7 \text { in } \\
\text { 2019.) }\end{array}$ & $12.2 \%$ & $60.5 \%$ & $27.3 \%$ & $5.1 \%$ & $55.4 \%$ & $39.4 \%$ & $8.2 \%$ & $53.8 \%$ & $39.0 \%$ \\
\hline
\end{tabular}




\begin{tabular}{|l|l|l|l|l|l|l|l|l|l|}
\hline Japan (Wave 5 in & $4.3 \%$ & $45.9 \%$ & $49.8 \%$ & $2.9 \%$ & $47.3 \%$ & $49.9 \%$ & $6.2 \%$ & $47.7 \%$ & $46.2 \%$ \\
2005, Wave 6 in \\
2010; Wave 7 in \\
2019.)
\end{tabular}

Source: Data come from Waves 5, 6 and 7 of the World Values Survey. 
All in all, our findings presented above suggest that in China, a majority or over $70 \%{ }^{9}$ of the population believed in none (0) or a very small portion (1-2) of postmaterialist values measured in the three waves of the WVS conducted in China, while only less than $30 \%$ of the population had positive feelings about most or all of those values. Such a level seemed quite low, particularly in comparison with the levels in the other three East Asian societies. These findings seem to support Inglehart's argument that as a society becomes increasingly modernized with respect mainly to economic development, the level of postmaterialist values will increase in the society. Since Japan, South Korea and Taiwan (as "upper-income" societies) in general have had been more modernized than China (as "upper-middle-income), ${ }^{10}$ all those three East Asian societies have had enjoyed higher levels of postmaterialist values than China, particularly since 2013, as demonstrated in Table 2.

IV. The Origins of Postmaterialist Values

There are quite a few factors that could play an important role in creating and shaping postmaterialist values, such as age, education, gender, and income. However, we are particularly

${ }^{9}$ As data presented in Tables 1 and 2 indicate, over $10 \%$ and $60 \%$ of the respondents in the three surveys conducted in China chose none and only one to two of postmaterialist values.

${ }^{10}$ See Table E on page 148 of United Nations: World Economic Situation and Prospects 2014 (https://www.un.org/en/development/desa/policy/wesp/wesp_current/2014wesp_country_classifi cation.pdf), which lists mainland China as an "upper-middle-income" society and the other three East Asian societies as "upper-income" societies. 
interested in the intergenerational sociocognitive effect on those values for the purpose of examining and testing Inglehart's key proposition that postmaterialist values are derived mainly from generations who take physical or material security for granted and hence focus on postmaterialist needs since they grew up without constant concerns over material scarcity.

To test this proposition, we classify our respondents in the three surveys into three birth cohorts: (1) those who were born in and after 1990, (2) those who were born between1960 and 1989, and (3) those who were born in and before the 1959. These cohorts are determined according to three discernable major stages of economic development in contemporary China. ${ }^{11}$ As Figure 1 shows, China's income per capita grew very slowly during the 1960s and 1970s, faster in the 1980s and the early 1990s, and then fastest since the early 1990s. Thus, those who were born in and after the 1990s were supposed to enjoy the highest level of material security or prosperity in their preadult years and hence were likely to have the highest level of postmaterialist values. Following the same logic, those who were born between the 1960s and 1980s had a higher level of economic security in their preadult years and therefore were likely to have a higher level of postmaterialist values than those who were born in and before the 1950s

${ }^{11}$ It should be noted that due to the lack of clear consensus on the start of people's impression years (IYs), there could be many alternative age points that one could use to divide the respondents into the three cohorts. To test Inglehart's original proposition on the cohort effect we here follow his approach to the classification of cohorts (i.e., classifying them based on birth years). The results of our analyses of the three cohorts based on different age points are consistent with those presented in Figure 2 and Table 3. 
and spent most of their preadult years in the 1950s and 1960s when China's economy grew slowest compared to that in the 1970s, 1980s, and 1990s.

Figure 2 reports the results of a crosstabulation between postmaterialist values and the three birth cohorts or generations. These results are consistent with our expectation derived from Inglehart's original proposition: the younger generations tend to have higher levels of postmaterialist values than the older generations in China. Specifically, the percentage of each cohort possessing a medium/high level of postmaterialist values in China increased from a low of $20 \%$ of the oldest cohort (born in and after 1959) to a medium of $27 \%$ of the middle cohort (born between 1960 and 1989) to a high of over $29 \%$ of the youngest cohort (born after the 1990s). In other words, the younger the generation was, the higher level of postmaterialist values was. This relationship between the generational change and the level of postmaterialist values was also substantiated by a strong correlation coefficient (gamma $=.57)$ presented in Figure 2.

It should be noted, however, that the differences in postmaterialist values (1) between the pre-1959 and the 1960-1989 generations and (2) between the pre-1959 and the post-1990 generations seemed bigger than the difference between the two younger generations. There might be at least two reasons for such a discrepancy. One is that the difference between the level of economic security experienced by the oldest generation (i.e., the pre-1959 generation) and that experienced by each of the two younger generations (i.e., the 1960-1989 and the post-1990 generations) is much greater than the difference between the levels of economic security experienced by the two younger generations due to the varying paces of economic development in China since the outset of post-Mao economic reforms in the late 1970s and 1980s. The other reason might be that the Chinese Communist Party (CCP) have stepped up the political indoctrination of young people in the school systems and later social media since the 1989 
Tiananmen Democracy Movement, particular under Xi Jinping's rule (see, e.g., Harmel and Yeh 2015; Dittmer 2020; Shan and Chen 2020). The indoctrination might have somewhat damped the level of postmaterialist values within the youngest generation, which otherwise could have been higher than that found in this study.

\section{Figure 2}

\section{Generational Effect on Postmaterialist Values}

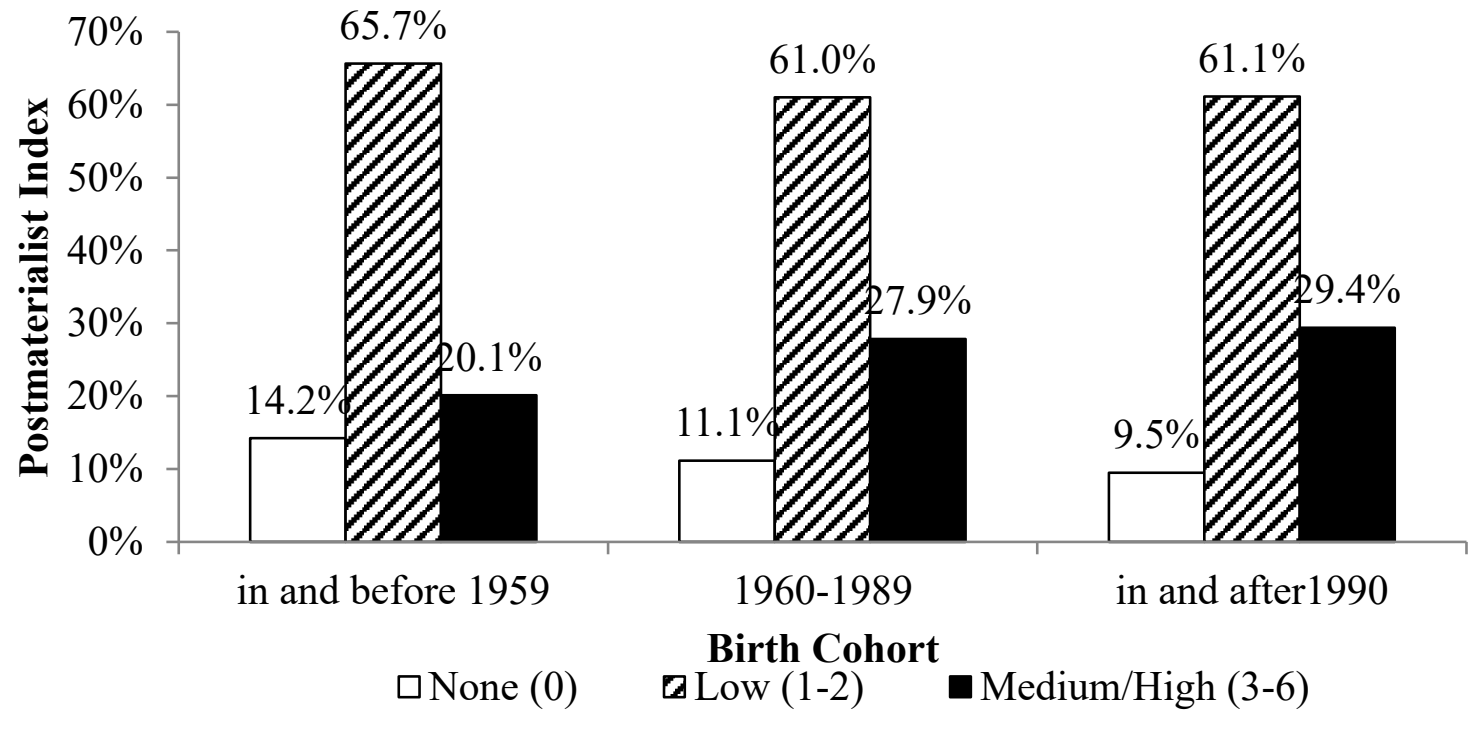

Source: Combined data from the 2007, 2013 and 2018 World Values Surveys in China.

Note: $\mathrm{N}=6309$; gamma $=.57$ (at the significance level of 0.00 ).

To determine the independent effect of generation on postmaterialist values in China, we run ordered-logistic regression models controlling for survey periods and several other key demographic variables, such as sex, education, income and social class. The results from Models 1 to 3, presented in Table 3, clearly indicate that generation has an independent and significant 
impact on postmaterialist values, even after controlling for the other variables: the respondents of the younger cohorts (i.e., those who were born between 1960 and 1989, and those who were born in and after 1990) had a stronger belief in postmaterialism than did those of the oldest cohort (i.e., those who were born in and before 1959).

Table 3:

Ordered-Logistic Regressions of Postmaterialist Values by Generations, Survey Periods, and Other Demographic Factors

\begin{tabular}{|c|c|c|c|}
\hline & & $\begin{array}{l}\text { laterialist } v \\
\mathrm{ow}=1 ; \mathrm{me}\end{array}$ & \\
\hline & Model 1 & Model 2 & Model 3 \\
\hline Birth cohort: ${ }^{a}$ & & & \\
\hline Born 1960-1989 & $0.336^{* * *}$ & $0.342 * * *$ & $0.316^{* * *}$ \\
\hline & $(0.059)$ & $(0.059)$ & $(0.066)$ \\
\hline Born in/after 1990 & $0.395 * * *$ & $0.417 * * *$ & $0.309 * * *$ \\
\hline & $(0.093)$ & $(0.095)$ & $(0.105)$ \\
\hline Survey period: ${ }^{b}$ & & & \\
\hline 2013 (Wave 6 of WVS) & & -0.070 & -0.112 \\
\hline & & $(0.071)$ & $(0.082)$ \\
\hline 2018 (Wave 7 of WVS) & & -0.071 & -0.081 \\
\hline & & $(0.067)$ & $(0.077)$ \\
\hline $\operatorname{Sex}^{c}$ & & & 0.031 \\
\hline & & & $(0.055)$ \\
\hline Education $^{d}$ & & & $0.286^{* * *}$ \\
\hline & & & $(0.073)$ \\
\hline Income & & & -0.004 \\
\hline
\end{tabular}


(0.019)

Social class ${ }^{e}$

0.045

$(0.042)$

$\begin{array}{lccr}\text { Intercepts } & & & -1.748^{* * *} \\ (\text { none }) \mid(\text { low }) & -1.807 * * * & (0.071) & (0.118) \\ & (0.056) & 1.205 * * * & 1.339 * * * \\ (\text { low }) \mid(\text { medium/high }) & 1.254 * * * & (0.068) & (0.116) \\ & (0.052) & 11321.760 & 9855.025 \\ \text { AIC } & 11319.038 & 11362.258 & 9921.175 \\ \text { BIC } & 11346.037 & -5654.880 & -4917.512 \\ \text { Log } L . & -5655.519 & 11309.760 & 9835.025 \\ \text { Deviance } & 11311.038 & 6309 & 5514 \\ N . & 6309 & 5\end{array}$

Note: ${ }^{* * *} p<.01$.

${ }^{a}$ Those born in and before 1959 as the reference group.

${ }^{b} 2007$ Survey as the reference group.

${ }^{c} 0=$ male; $1=$ female.

${ }^{d} 0=$ below college; $1=$ college and above.

${ }^{e} 1$ = lower; 2 = lower-middle; 3 = middle; 4 = upper-middle; 5 = upper.

Source: Data are pooled from the Waves 5, 6 and 7 of the WVS conducted in China in 2007, 2013 and 2018, respectively.

Moreover, following the strategy of APC analysis, we included the survey periods (Waves 5, 6 and 7 in 2007, 2013 and 2018, respectively) in Models 2 and 3. The results indicate that the survey periods did not exert any significant impact on the level of postmaterialist values. 
In other words, the level of postmaterialist values within each generational cohort did not change significantly across all the three surveys. These results suggest that age, which progresses over the survey periods, did not significantly influence the level of postmaterialist values in our samples. $^{12}$

In addition, among all the control variables, education exerted a significant, positive impact on postmaterialist values. Those who have acquired college education or above tend to have a stronger belief in postmaterialist values. This finding confirms findings from other survey studies employing Inglehart's original measure of postmaterialist values (e.g., Inglehart 1990; Gibson et al. 1994). ${ }^{13}$

In sum, the evidence from the three surveys strongly supports our expectation that in China, postmaterialist values result from the generational change. Younger generations in China, like those in other countries, tend to have a higher level of postmaterialist values than older generations, because the former enjoyed higher levels of economic security in their preadult years.

V. The Attitudinal and Behavioral Impact of Postmaterialist Values

Based on Inglehart's argument on the impact of postmaterialist values on political attitudes and behavior, we expect that in China, those who have a strong belief in postmaterialist values tend to have a lower level of trust in government and have a stronger tendency to

\footnotetext{
${ }^{12}$ For estimated effects of birth cohorts and survey periods, see Appendix B.

13 For the correlation matrix of key covariates, see Appendix C.
} 
participate in unconventional political activities. We now test this expectation against data collected from the three national surveys.

To measure trust in government, we used seven questions on the respondents' confidence in various governmental institutions. Specifically, respondents were asked to register their level of trust on a 4-point scale, where "1" indicates the lowest level and " 4 " refers to the highest, in the following governmental structures:

1. The national government

2. The Party (Chinese Communist Party)

3. The armed forces

4. The police

5. The legislature (National People's Congress)

6. The courts

7. Civil services (administrative agencies)

These seven items were then combined to form an additive index to capture a collective profile of a respondent's trust in government at the national level, ranging from 7 to $28 .{ }^{14}$ This index is used in the bivariate and multivariate analyses that follow. The validity of the main themes of these items measuring trust in government has been confirmed by survey studies conducted in

\footnotetext{
${ }^{14}$ It should be noted that some earlier studies of political trust in China find that there are important theoretical and empirical differences between trust in the central government and trust in local governments (e.g., Li 2016). In this study, however, we focus mainly on trust in government and political institutions at the national level, as the index indicates.
} 
different cultural and political settings (e.g., Inglehart 1997; Chen 2004; Wang 2005; Wang and You 2016; Wong et al. 2011; You and Wang 2020).

To test our expectation, we first ran a crosstabulation between the indexes of trust in government and postmaterialist values. The results of the crosstabulation are presented in Table 4. Overall, the pattern shown in that table supports our expectation. The level of postmaterialist values decreased as the level of trust in government increased. For example, while $46 \%$ of those who had no support for postmaterialist values scored "high" for trust in government, a significantly smaller percentage (39\%) of those who scored "medium/high" for those values registered a "high" level of trust. In addition, the gamma had a significant, negative sign, indicating a negative relationship between postmaterialist values and trust in government.

Table 4

Correlation between Political Trust and Postmaterialist Values

$$
\text { Postmaterialist Index }
$$

None (0) Low (1-2) Medium/High (3-6)

\begin{tabular}{lcccc}
\hline & Low (7-15) & $18.3 \%$ & $19.9 \%$ & $27.6 \%$ \\
Political Trust & Middle (15-21) & $36.0 \%$ & $36.3 \%$ & $33.2 \%$ \\
& High (22-28) & $45.7 \%$ & $43.8 \%$ & $39.3 \%$ \\
\hline & & & \\
\hline & & & \\
& &
\end{tabular}

Note: $* * * P<.001$.

Source: Combined data from the 2007, 2013 and 2018 World Values Surveys in China. 
To gauge the level of participation in unconventional political activities, the respondents were asked to indicate whether they had participated or planned ${ }^{15}$ to participate in any number of four types of political activities:

1. Signing a petition

2. Joining boycotts

3. Attending demonstrations

4. Joining unofficial strikes

Compared to other types of political participation (e.g., voting in elections for local People's Congresses), these forms of participation require more initiative, determination, time, and communication skills. In addition, although these forms are considered legal in China, they are not risk-free. Some government officials and agencies targeted by any of these forms of political participation may consider these activities as serious challenges to their authority and hence retaliate against participants (Chen 2014, 130). Finally, as not all these forms of political participation have been fully institutionalized, they have required more creativity and effort (see, Li 2008). Thus, the types of activities listed above have been typically consider unconventional political activities in China (see, also, Shi 1997; Chen 2004).

15 The same measurement, which combined both "participated" and "planned to participate," has been used by Inglehart $(1997,211)$ to detect the impact of postmaterialist values on unconventional political behavior. To test Inglehart's original hypothesis about such an impact, therefore, we keep our measurement comparable to Inglehart's. 
These four items were combined to form an additive index to capture a collective profile of a respondent's activism in conventional political participation, ranging from 0 (the lowest level ) to 4 (the highest level). The index is used in the bivariate and multivariate analyses that follow. ${ }^{16}$ These questions and similar versions of them have been employed in the WVS (see, e.g., Inglehart 1997) and the Political Action Surveys (see, Barnes, Kaase, et al. 1979), respectively, to measure unconventional political participation. While these types of activities do not exhaust all kinds of unconventional political behaviors in China, they do together provide a valid indicator of unconventional political participation among the respondents. Some earlier studies of political participation in China indicate that although those types of activities are not engaged in by a large number of people, they provide political activists with meaningful and actionable options to address some critical social and political issues (e.g., O’Brien 1996; O’Brien and Li 2011).

We ran another crosstabulation between the indexes of unconventional political participation and postmaterialist values based on data pooled from the three national surveys (see Table 5). As hypothesized earlier, those who have a stronger belief in postmaterialist values tend to be more active in participating in unconventional political activities. For instance, while only $27 \%$ of those who did not believe in anyone of postmaterialist values measured in the surveys were in the "high" category of unconventional political participation, about $35 \%$ of those who felt positive or very positive about those values were in that category. Again, the gamma had a

16 We also created an alternative index that took respondents of only actual participation into account. The results of the bivariate and multivariate analyses based on that index were consistent with the results reported in Tables 5 and 6 below. 
significant, positive sign, indicating that the two indexes were significantly, positively associated.

Table 5:

Correlation between Political Participation and Postmaterialist Values

\begin{tabular}{ccccc}
\hline & & & \multicolumn{2}{c}{ Postmaterialist Index } \\
& & None (0) & Low (1-2) & Medium/High (3-6) \\
\hline Nolitical Participation (0) & $48.1 \%$ & $45.3 \%$ & $39.5 \%$ \\
& Medium (1-2) & $24.7 \%$ & $24.7 \%$ & $25.7 \%$ \\
& High (3-4) & $27.2 \%$ & $30.0 \%$ & $34.8 \%$ \\
\hline & & gamma $=.36^{* * *}$ & \\
\hline
\end{tabular}

Note: $* * * P<.001$

Source: Combined data from the 2007, 2013 and 2018 World Values Surveys in China.

To determine the independent impact of postmaterialist values on trust in government and unconventional political participation, we run ordered-logistic regression analyses. Due to the inclusion of key demographic factors like age, sex, social class, income, and education as control variables, these ordered-logistic regression analyses can be considered strong tests of the independent impact of postmaterialist values. The results of the analyses are presented in Table 6.

Table 6: 
Ordered-Logistic Regressions of Trust in Government and Unconventional Political Participation by Postmaterialist Values and Demographic Factors

\begin{tabular}{|c|c|c|c|c|}
\hline & \multicolumn{2}{|c|}{ Trust in Government } & \multicolumn{2}{|c|}{$\begin{array}{c}\text { Unconventional Political } \\
\text { Participation }\end{array}$} \\
\hline & Model 1 & Model 2 & Model 3 & Model 4 \\
\hline \multirow[t]{2}{*}{ Postmaterialist values } & $-0.207^{* * *}$ & $-0.195^{* * *}$ & $0.191^{* * *}$ & $0.094^{* *}$ \\
\hline & $(0.041)$ & $(0.044)$ & $(0.044)$ & $(0.047)$ \\
\hline \multirow[t]{2}{*}{ Age } & & $0.012^{* * *}$ & & $-0.030^{* * *}$ \\
\hline & & $(0.002)$ & & $(0.002)$ \\
\hline \multirow[t]{2}{*}{$\operatorname{Sex}^{a}$} & & 0.061 & & -0.056 \\
\hline & & $(0.053)$ & & $(0.056)$ \\
\hline \multirow[t]{2}{*}{ Education $^{b}$} & & -0.071 & & $0.269^{* * *}$ \\
\hline & & $(0.070)$ & & $(0.075)$ \\
\hline \multirow[t]{2}{*}{ Income } & & $-0.035^{*}$ & & -0.017 \\
\hline & & $(0.018)$ & & $(0.019)$ \\
\hline \multirow[t]{2}{*}{ Social class ${ }^{c}$} & & $0.148^{* * *}$ & & $0.082^{*}$ \\
\hline & & $(0.041)$ & & $(0.044)$ \\
\hline \multicolumn{5}{|l|}{ Intercepts } \\
\hline \multirow[t]{2}{*}{ low $\mid$ medium } & $-1.519^{* * *}$ & $-0.780^{* * *}$ & -0.019 & $-1.366^{* * *}$ \\
\hline & $(0.058)$ & $(0.142)$ & $(0.059)$ & $(0.151)$ \\
\hline medium | high & 0.053 & $0.792^{* * *}$ & $1.025^{* * *}$ & -0.237 \\
\hline
\end{tabular}




\begin{tabular}{lcccc} 
& $(0.054)$ & $(0.142)$ & $(0.061)$ & $(0.150)$ \\
AIC & 12098.1 & 10723.9 & 10421.5 & 9372.0 \\
BIC & 12118.0 & 10776.1 & 10441.0 & 9423.3 \\
Log $L$. & -6046.0 & -5353.9 & -5207.7 & -4678.0 \\
Deviance & 12092.1 & 10707.9 & 10415.5 & 9356.0 \\
$N$. & 5700 & 5082 & 4873 & 4496 \\
\hline
\end{tabular}

Note ${ }^{*} p<0.10 ;{ }^{* *} p<0.05 ;{ }^{* * *} p<0.01$

${ }^{a} 0=$ male; $1=$ female

${ }^{b} 0=$ below college; $1=$ college and above.

${ }^{c} 1=$ lower; $2=$ lower-middle; $3=$ middle; $4=$ upper-middle; 5 = upper.

Source: Data are pooled from the Waves 5, 6 and 7 of the WVS conducted in China in 2007, 2013 and 2018, respectively.

Overall, the results from Models 1 to 4 unequivocally confirm our expectation that those who enjoy a higher level of postmaterialist values tend to be more critical of the government, and more active in engaging in unconventional political activities than do those who have negative or lukewarm feelings about those values. Specifically, the strength of postmaterialism measured by the index of postmaterialist values did have a statistically significant, negative impact on trust in government even after controlling for key demographic variables (see Models 1 and 2). The results from Model 3 and 4 show that the strength of postmaterialism exerted a statistically significant, positive effect on the level of engagement in unconventional political activities controlling for the same demographic factors. In addition, it is worth noting the results of some 
demographic variables (as control variables) from both models. From Model 2, one can learn that those who were older, and who were in higher social classes tended to have a higher level of trust in government. In Model 4, it was clear that those who were younger, whose incomes were somewhat lower (e.g., migrant workers), and who had higher education were more likely to participate in unconventional political activities.

\section{Conclusion and Discussion}

As China has experienced a sustained period of economic growth since the outset of postMao reforms, has a transforming phenomenon, known as a "silent revolution," happened in that country? To answer this critical question, we examined the level and origin of postmaterialist values and the attitudinal and behavioral impact of those values in China based on the three longitudinal, cross-sectional national surveys conducted in a period of ten years, from 2007 to 2018. The findings show that while the current level of postmaterialist values in China remains quite low, particularly compared to the levels of those values in some of its counterparts in East Asia as well as those in the West, ${ }^{17}$ such values seem to have already flourished in the younger generations who took economic security for granted in their preadult years. These findings concur with what Inglehart $(2018,30)$ recently claimed concerning the generational effect on the development of postmaterialist values in China: "a shift toward Postmaterialist values will take

\footnotetext{
${ }^{17}$ Based on data from the World Values Surveys, Inglehart $(2018,30)$ has concluded that compared to Western countries, China still has a "tiny minority" of the population believing postmaterialism.
} 
place when a younger generation emerges that has grown up taking survival for granted.” Thus, one can predict that given the continuation of economic growth, as younger generations gradually replace older generations, postmaterialist values will eventually become more prevalent than they are now in China. More specifically, if one follows Inglehart's projected timeline - "four or five decades" (Inglehart 2018, 143) of sufficient economic growth — in which a country would experience a significant rise in the level of postmaterialist values, one may even venture to predict that China is likely to experience such a substantial increase in those values in next one or two decades since that country has already experienced an rapid and continuous growth in income per capita since the early 1990s (see Figure 1).

Moreover, we have found that postmaterialist values do play an important role in shaping individuals' political attitudes and behavior. Specifically, consistent with Inglehart's conviction, those who strongly believe in postmaterialist values tend to be critical of the government and active in taking part in unconventional political activities. As younger generations continue to replace older generations, the portion of the population believing in postmaterialist values will increase; in turn, the number of people who are critical of governmental authorities and actively seeking and even creating unconventional channels to influence political decision making will increase. Indeed, a voluminous literature on unconventional political activities in China has already documented that the Chinese government has been facing increasingly intensified criticisms from an increasing portion of the population and confront an upsurge of unconventional political activities like popular petitions, protests, and boycotts (e.g., Fu 2017; Li 2008; Lorentzen 2017; O’Brien and Li 2006). These changes will no doubt present serious challenges to the regime as well as many policies implemented by the regime. How the regime copes with these challenges will have a lot to do with the future of this most populous and 
dynamic country. All in all, we conclude that a "silent revolution," as Inglehart described in the West five decades ago, has seemed in the making in China. As such a revolution unfolds, the nature of politics will change fundamentally in that county. 


\section{APPENDIX A}

Table A1: Descriptive Statistics

\begin{tabular}{|c|c|c|c|c|c|}
\hline Variable & $N$ & Minimum & Maximum & Mean & $\begin{array}{l}\text { Std. } \\
\text { Deviation }\end{array}$ \\
\hline $\begin{array}{l}\text { Postmaterialist values ( } 3 \text { levels: } \\
\text { None }=0 ; \text { low }=1 \text {; medium } / \text { high }= \\
\text { 2.) }\end{array}$ & 6309 & 0.00 & 2.00 & 1.156 & 0.600 \\
\hline $\begin{array}{l}\text { Political Trust ( } 3 \text { levels: low }=1 ; \\
\text { medium }=2 ; \text { high }=3 \text {.) }\end{array}$ & 6247 & 1.00 & 3.00 & 2.213 & 0.775 \\
\hline $\begin{array}{l}\text { Political participation }(3 \text { levels: } \\
\text { none }=0 ; \text { medium }=1 ; \text { high }=2 \text { ) }\end{array}$ & 5185 & 0.00 & 2.00 & 0.849 & 0.856 \\
\hline Age (18-75) & 7327 & 18 & 75 & 44.412 & 14.334 \\
\hline Born 1900-1959 & 1670 & -- & -- & -- & -- \\
\hline Born 1960-1989 & 3986 & -- & -- & -- & -- \\
\hline Born in/after 1990 & 653 & -- & -- & -- & -- \\
\hline Sex $(0=$ male; 1 = female. $)$ & 7327 & 0.00 & 1.00 & 0.536 & 0.499 \\
\hline $\begin{array}{l}\text { Education }(0=\text { below college; } 1= \\
\text { college and above. })\end{array}$ & 6600 & 0.00 & 1.00 & 0.180 & 0.384 \\
\hline $\begin{array}{l}\text { Income (10 self-identified levels: } \\
\text { from } 1 \text { as the lowest level to } 10 \text { as } \\
\text { the highest level) }\end{array}$ & 6642 & 1 & 10 & 4.186 & 1.859 \\
\hline $\begin{array}{l}\text { Social class }(5 \text { levels: lower class }= \\
1 ; \text { lower-middle }=2 ; \text { middle class }=\end{array}$ & 6997 & 1.00 & 5.00 & 2.315 & 0.836 \\
\hline
\end{tabular}


3; upper-middle class $=4$; upper

class $=5$.) 


\section{APPENDIX B}

FIGURE B1: Estimated effects of Generations and Survey Periods

Predicted effects of birth cohorts

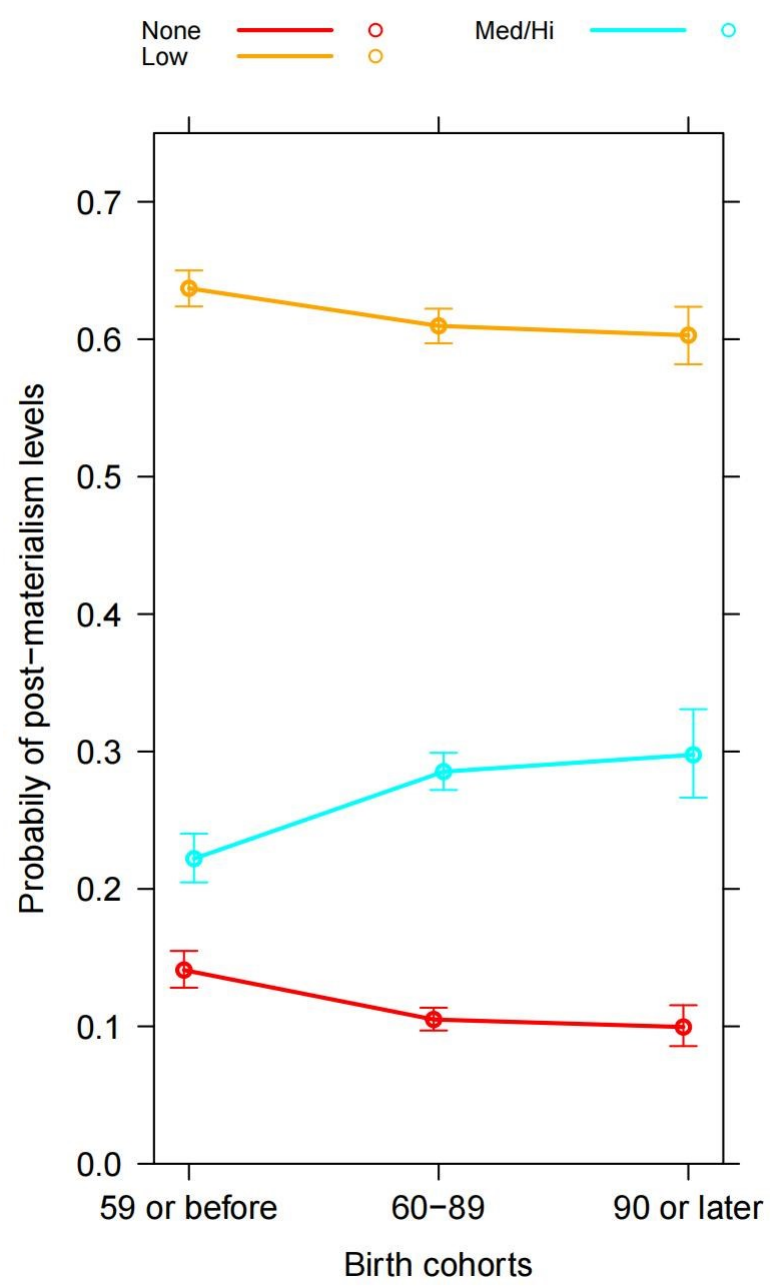

Predicted effects of survey waves

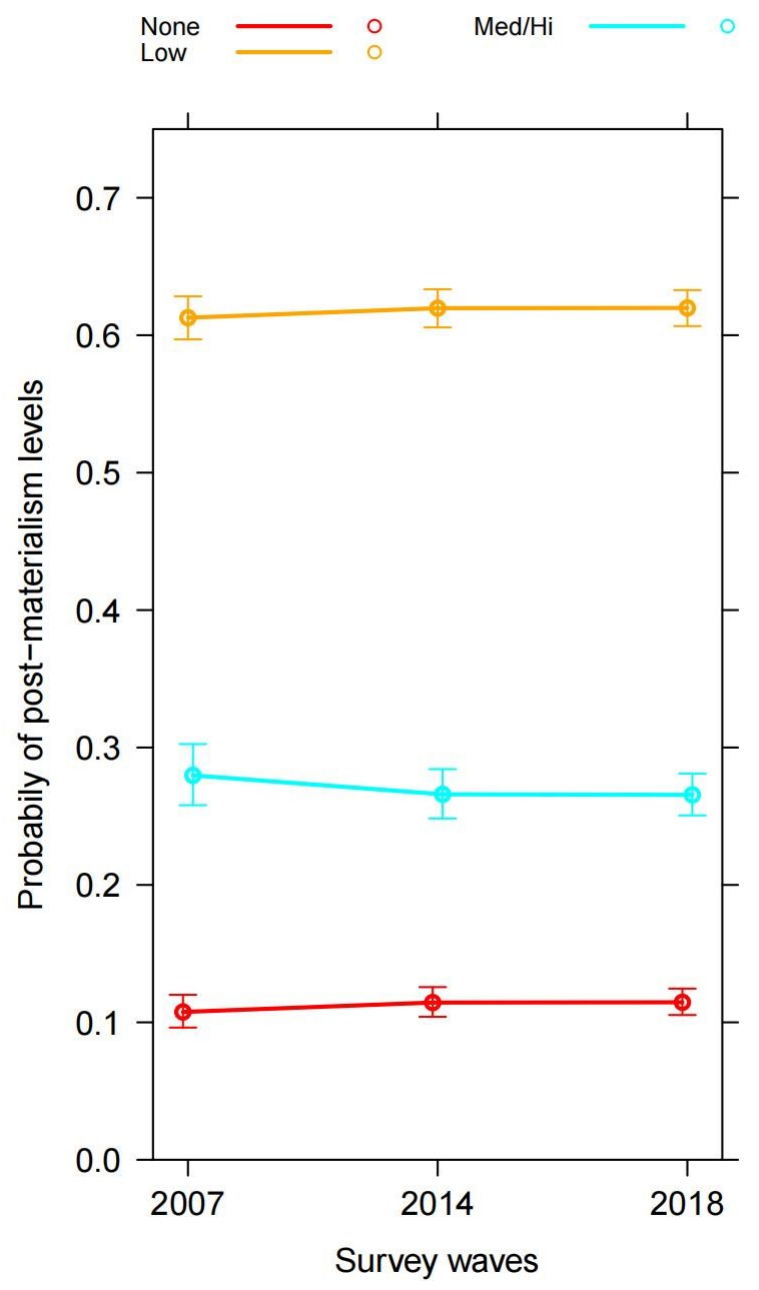




\section{APPENDIX C}

Table C1: Correlation Matrix of Key Covariates (Spearman rho)

\begin{tabular}{|c|c|c|c|c|}
\hline & Sex & Education & Income & Social class \\
\hline Sex & & -0.01 & 0.01 & $0.03^{* *}$ \\
\hline Education & & & $0.21^{* * * *}$ & $0.19^{* * *}$ \\
\hline Income & & & & $0.62^{* * *}$ \\
\hline Social class & & & & \\
\hline
\end{tabular}

Note: ${ }^{*} p<0.10 ;{ }^{* *} p<0.05 ;{ }^{* * *} p<0.01$ 


\section{REFERENCES}

Abramson, Paul R. and Ronald Inglehart. 1995. Values Change in Global Perspective. Ann Arbor, Mich.: University of Michigan Press.

Barnes, Samuel, Max Kaase, et al. 1979. Political Action. Beverly Hills, CA: Sage.

Brym, R. 2016. "After Postmaterialism: An Essay on China, Russia and the United States." Canadian Journal of Sociology 41:2,195-211.

Chang, Chun-Chih and Te-Sheng Chen. 2013. "Idealism versus Reality: An Empirical Test of Postmaterialism in China and Taiwan." Issues \& Studies 49:2, 63-102.

Chen, Jianan and Lanying Sun. 2019. “ Media Influence on Citizens' Government Trust: A Cross-Sectional Data Analysis of China." International Journal of Public Administration $42: 13,1122-34$

Chen, Jie. 2004. Popular Political Support in Urban China. Stanford, CA: Stanford University Press.

Chen, Jie. 2014. A Middle Class without Democracy: Economic Growth and the Prospects for Democratization in China. New York: Oxford University Press.

Dittmer, Lowell. 2020. "On the Sixth Generation: Preliminary Speculations about Chinese Politics after Xi." Journal of Contemporary China 29:122, 253-65.

Harmel, Robert and Yao-Yuan Yeh. 2016. "Attitudinal Differences within the Cultural Revolution Cohort: Effects of the Sent-down Experience.” The China Quarterly 225 (Mar.), 234-52.

Fu, Diana. 2017. "Disguised Collective Action in China." Comparative Political Studies 50:4, 499-527. 
Gibson, James L. and Raymond M. Duch. 1994. "Postmaterialism and the Emerging Soviet Democracy." Political Research Quarterly 47:1, 5-39.

Inglehart, R. 1971. "The Silent Revolution in Europe: Intergenerational Change in PostIndustrial Societies.” American Political Science Review 65:4, 991-1017.

Inglehart, R. 1977. The Silent Revolution: Changing Values and Political Styles Among Western Publics. Princeton, New Jersey: Princeton University Press.

Inglehart, R., C. Haerpfer, A. Moreno, C. Welzel, K. Kizilova, J. Diez-Medrano, M. Lagos, P. Norris, E. Ponarin \& B. Puranen et al., eds. 2014. World Values Survey: All Rounds Country-Pooled Datafile 1981-2014. Madrid: JD Systems Institute. Version: http://www.worldvaluessurvey.org/WVSDocumentationWV

Inglehart, Ronald F. 2018. Cultural Evolution: People's Motivations Are Changing, and Reshaping the World. Cambridge University Press.

Inglehart, Ronald F., and Christian Welzel. 2005. Modernization, Cultural Change, and Democracy: The Human Development Sequence. New York: Cambridge University Press.

Inglehart, Ronald and Renata Siemienska. 1988. "Changing Values and Political Dissatisfaction in Poland and the West: A Comparative Analysis." Government and Opposition 23:4, 440-57.

Inglehart, Ronald. 1997. Modernization and Postmodernization: Cultural, Economic, and Political Change in 43 Societies. Princeton, N.J.: Princeton University Press.

Inglehart, Ronald.1990. Cultural Shift in Advanced Industrial Society. Princeton: Princeton University Press. 
Jennings, M. 1997. "Political Participation in the Chinese Countryside." American Political Science Review 91:2, 361-72.

Li, Lianjiang. 2008. "Political Trust and Petitioning in the Chinese Countryside." Comparative Politics 40:2, 209-26.

Li, Lianjiang.. 2016. "Reassessing Trust in the Central Government: Evidence from Five National Surveys." The China Quarterly 225, 100-121.

Lorentzen, Peter. 2017. "Designing Contentious Politics in Post-1989 China." Modern China 43:5, 459-493.

Lu, Jia Li Qi and Xin Yu. 2019. "Political Trust in the Internet Context: A Comparative Study in 36 Countries." Government Information Quarterly 36:4, 1-10.

Lu, Jie and Bruce Dickson. 2020. "Revisiting the Eastonian Framework on Political Support: Assessing Different Measures of Regime Support in Mainland China." Comparative Politics 52:4, 671-701.

Maslow, Abraham H. 1954. Motivation and Personality. New York: Harper.

Nathan, Andrew. 2015. "The Puzzle of the Chinese Middle Class." Journal of Democracy $27: 2,20-41$.

Neundorf, Anja and Richard G. Niemi. 2014. "Beyond Political Socialization: New Approaches to Age, Period, Cohort Analysis." Electoral Studies 33, 1-6.

Neundorf, Anja and Kaat Smets. 2017. "Political Socialization and the Making of Citizens." Oxford Handbooks Online.

Norris, Pippa. 1999. “Introduction: The Growth of Critical Citizens?” In Critical Citizens: Global Support for Democratic Government, eds. Pippa Norris. New York: Oxford University Press, 1-27. 
Norris, Pippa. 2011. Democratic Deficit: Critical Citizens Revisited. New York: Cambridge University Press.

O’Brien, Kevin J. and Lianjiang Li. 1995. "The Politics of Lodging Complaints in Rural China.” China Quarterly 143, 756-83.

O'Brien, Kevin J. and Lianjiang Li. 2006. Rightful Resistance in Rural China. Cambridge and New York: Cambridge University Press.

O'Brien, K. 1996. “Rightful Resistance.” World Politics 49:1, 31-55.

Shan, Wei and Juan Chen. 2020. "Westernized but Not Yet Pro-Democracy: The Younger Generations in China and Implications for Future Leadership." China: An International Journal 18:1, 46-62.

Shi, Tianjian. 1997. Political Participation in Beijing. Cambridge, M.A.: Harvard University Press.

Tang, Wenfang. 2016. Populist Authoritarianism: Chinese Political Culture and Regime Sustainability. New York: Oxford University Press.

Verba, Sidney, Norman Nie and Jae-on Kim. 1978. Participation and Political Equality: A Seven-Nation Comparison. New York: Cambridge University Press.

Wang, Zhengxu and Yu You. 2016. "The Arrival of Critical Citizens: Decline of Political Trust and Shifting Public Priorities in China." International Review of Sociology 26:1, 105-24.

Wang, Zhengxu. 2005. "Before the Emergence of Critical Citizens: Economic Development and Political Trust in China." International Review of Sociology 15:1, 155-71.

Wong, Timothy Ka-ying, Po-san Wan and Hsin-Huang Michael Hsiao. 2011. “The Bases of Political Trust in Six Asian Societies: Institutional and Cultural Explanations Compared.” International Political Science Review 32:3, 263-81. 
You, Yu and Zhengxu Wang. 2020. “The Internet, Political Trust, and Regime Types: a Crossnational and Multilevel Analysis.” Japanese Journal of Political Science 21, 68-89.

Zhang, Tony Huiquan, Robert Brym and Robert Andersen. 2017. "Liberalism and Postmaterialism in China: The Role of Social Class and Inequality." Chinese Sociological Review 49:1, 65-87.

Zhou, Yingnan Joseph. 2020. "Is China a Deviant Case? A Societal-Level Test of the Modernization Theory," Political Studies 69:4, 834-857. 